\title{
The dark and the bright sides of proactive work behaviour and situational constraints: Longitudinal relationships with task conflicts
}

\author{
Anne Spychala \\ Institute for Leadership and Human Resource Management, \\ University of St. Gallen, St. Gallen, Switzerland \\ Sabine Sonnentag
Department of Psychology, University of Konstanz, Konstanz, Germany
}

We investigated relationships of a job stressor (situational constraints) and specific proactive behaviours with change in task conflicts over time. We introduced two distinct types of proactive work behaviour (promotionoriented initiative and prevention-oriented initiative) and examined their positive but also negative relationships with change in task conflicts. Study 1 supported the construct validity of promotion-oriented initiative and prevention-oriented initiative for 363 student assistants: Confirmatory factor analyses indicated that both types of proactive behaviour were distinct constructs and also distinct from active coping; patterns of correlations were similar to those of a prior concept of proactive behaviour. Study 2 was a longitudinal online survey with 197 employees over 3 weeks. Consistent with our hypotheses, situational constraints and promotion-oriented initiative predicted an increase in task conflicts, whereas prevention-oriented initiative predicted a decrease in task conflicts.

Keywords: Hindrance stressors; Prevention-oriented initiative; Proactive behaviour; Promotion-oriented initiative; Situational constraints; Task conflicts.

\footnotetext{
Correspondence should be addressed to Anne Spychala, University of St. Gallen, Institute for Leadership and Human Resource Management, Dufourstr. 40a, CH-9000 St. Gallen, Switzerland. E-mail: anne.spychala@unisg.ch

We would like to thank Carmen Binnewies, Anneloes M. L. Raes, and Jennifer L. Sparr for their helpful comments on earlier drafts of this article as well as Maike Debus, Mathilde van Haperen, Nora Liers, and Mandy Matthies for their support during data collection.
}

(C) 2011 Psychology Press, an imprint of the Taylor \& Francis Group, an Informa business http://www.psypress.com/ejwop http://dx.doi.org/10.1080/1359432X.2010.487646 
Today's jobs are typically characterized by rapid changes including the introduction of innovations and new technologies (Campbell, 2000; Thatcher \& Zhu, 2006). In addition, many employees work in companies with decentralized management and teamwork arrangements (Balogun \& Johnson, 2004; de Dreu \& Weingart, 2003; Schilling \& Steensma, 2001). Therefore, it is increasingly important that employees do not just fulfil their jobs and react passively to new situations but that they become more flexible and active, and that they address occurring problems in a proactive way (Parker, 2000; Swan \& Fox, 2009). Moreover, the ongoing changes imply an increase in job stressors (e.g., obstacles, job demands, role conflicts, uncertainty; Armenakis \& Bedeian, 1999; Härenstam et al., 2004; Jimmieson, Terry, \& Callan, 2004) as well as in interpersonal conflicts at work (e.g., task conflicts; de Dreu \& Weingart, 2003).

Recent research demonstrated the negative impact of task conflicts (i.e., conflicts with colleagues and supervisors about how to accomplish work tasks) on various outcomes including team performance, well-being, and satisfaction (e.g., de Dreu \& Weingart, 2003; Friedman, Tidd, Currall, \& Tsai, 2000; Gamero, González-Romá, \& Peiró, 2008; Medina, Munduate, Dorado, Martínez, \& Guerra, 2005). However, rather little is known about antecedents of task conflicts so far, and longitudinal studies are scarce (de Wit \& Greer, 2008; Moye \& Langfred, 2004; Peterson \& Behfar, 2003). The aim of this study is to fill this gap. Following research that emphasizes conflicts as a dynamic process (e.g., de Dreu, 2008; Greer, Jehn, \& Mannix, 2008; Jehn \& Mannix, 2001; Peterson \& Behfar, 2003; Simons \& Peterson, 2000), we examine antecedents that go along with a decrease or increase of task conflicts. Potential antecedents of such conflicts may derive from working conditions but also from employees' behaviour at work. Therefore, we examine stressors at work, especially situational constraints (i.e., obstacles in the work situation that hinder task accomplishment), and employees' proactive work behaviour as antecedents of increased task conflicts. We propose that situational constraints are directly related to increased task conflicts but that relationships for proactive work behaviour are less uniform.

Typically, researchers have studied proactive behaviour as positive and desired work behaviour. And indeed, there is evidence that proactive work behaviour is beneficial for individual as well as company success (Fay \& Frese, 2001; Raabe, Frese, \& Beehr, 2007). However, negative consequences of proactive work behaviour have rarely been addressed by researchersneither negative consequences on the employee him- or herself nor on colleagues, supervisors, or the company as a whole (for exceptions, see Bateman \& Crant, 1999; Campbell, 2000). We argue that proactive behaviour may have negative consequences particularly with respect to conflicts about how to accomplish work tasks because proactive employees 
might be "difficult" for colleagues and supervisors (cf. Grant, Parker, \& Collins, 2009). More specifically, we argue that consequences of proactive work behaviour are not uniformly positive or negative, but that relationships are different for distinct types of proactive work behaviour. Particularly, we introduce promotion-oriented initiative (i.e., discretionary behaviour that aims at taking control) and prevention-oriented initiative (i.e., discretionary behaviour that aims at preventing the reoccurrence of obstacles and stressors at work) as two specific types of proactive work behaviour. Promotion-oriented initiative should be related to increased task conflicts, whereas prevention-oriented initiative should be related to decreased task conflicts.

Altogether, our study contributes to the literature on interpersonal conflicts at work by examining their antecedents with a longitudinal design. Moreover, this study focuses on antecedents that may be modified (e.g., by job design efforts) instead of concentrating on mere team composition variables as prior research frequently has done (de Wit \& Greer, 2008). Furthermore, this study contributes to a deeper understanding of proactive work behaviour by analysing promotion-oriented and prevention-oriented initiative as specific proactive behaviours. More and more, research in this field demonstrates the importance of differentiating particular proactive behaviours (Griffin, Neal, \& Parker, 2007; Parker \& Collins, 2010), although the integration of dispersed streams of research under the umbrella of proactivity is also a major goal in proactivity research (e.g., Crant, 2000; Grant \& Ashford, 2008; Parker \& Collins, 2010).

\section{TASK CONFLICTS}

Interpersonal conflicts at work refer to a "process resulting from the tension between team members because of real or perceived differences" (de Dreu \& Weingart, 2003, p. 741). Research on conflicts at work usually distinguishes task conflicts (e.g., conflicts about procedures, policies, and distribution of resources) and relationship conflicts (e.g., conflicts about personal taste, political preferences, and values; de Dreu \& Weingart, 2003). Traditionally, task conflicts were seen as contributing to effective group decision making and group performance (Amason, 1996; Jehn, 1994), whereas relationship conflicts were seen as dysfunctional because they distract employees (de Dreu \& Weingart, 2003). However, recent research, including metaanalytical results, revealed that both types of conflicts go along with decreased job performance, well-being, and job satisfaction, as well as increased strain and tension (e.g., de Dreu, 2008; de Dreu \& Weingart, 2003; Friedman et al., 2000; Gamero et al., 2008; Medina et al., 2005). Even more important, researchers argued and empirically confirmed that relationship conflicts evolve from task conflicts due to misinterpretations of task conflict 
behaviour (i.e., if task conflict behaviour is perceived as personal criticism, relationship conflicts are likely to occur) and demonstrated that the negative impact of task conflicts on various outcomes is mediated by relationship conflicts (e.g., Friedman et al., 2000; Gamero et al., 2008; Medina et al., 2005). Therefore, especially task conflicts play a crucial role for work processes and performance as they often seem to be the starting point to unfavourable processes and outcomes at work. Because of this high importance of task conflicts, we will focus on perceived task conflicts in this study.

Although outcomes of conflicts are well elaborated, research on the antecedents of conflicts is scarce. Beyond performance feedback and information sharing which have been studied as potential antecedents (Moye \& Langfred, 2004; Peterson \& Behfar, 2003), previous research primarily focused on characteristics of team composition. Correspondingly, de Wit and Greer (2008) confirmed positive relationships between team diversity, especially informational diversity, and task conflicts in their meta-analysis. Other domains of potential antecedents are rarely investigated, yet. Moreover, from a practical perspective, knowledge about team composition variables as antecedents is often only of limited value as managers can influence team member characteristics primarily in the stage of team building. However, often it is necessary to influence detrimental characteristics also later on. Therefore, other factors have to come to the fore. In this study, we consider two main factors which may have an influence on a team's work and potential task conflicts: work environment and employees' behaviour. First, the environment in which teamwork takes place, especially job stressors, may have an influence. Typical job stressors refer to red tape and organizational politics as well as daily hassles, such as technical problems and missing or outdated information (e.g., LePine, Podsakoff, \& LePine, 2005). The concept of situational constraints represents these aspects. Thus, we examine situational constraints as a major antecedent of task conflicts at work. Second, team members themselves may have an influence on their work and potential conflicts. Although merely accomplishing one's job may be neutral for other team members, behaviour that goes beyond pure task accomplishment may evolve conflicts as it influences other team members' work. The concept of proactive behaviour depicts a form of work behaviour that goes beyond pure task accomplishment, for instance, by performing tasks in a proactive manner or by engaging in extra tasks (e.g., Grant \& Ashford, 2008; Parker \& Collins, 2010). Therefore, we incorporate proactive behaviour as another major antecedent of task conflicts into the study.

Finally, recent research emphasizes the dynamic nature of conflicts at work (e.g., de Dreu, 2008; Greer et al., 2008; Jehn \& Mannix, 2001; Peterson \& Behfar, 2003; Simons \& Peterson, 2000). For instance, with regard to task conflicts, Jehn and Mannix (2001) reported that medium to high levels 
during the midpoint of a group's work are beneficial for team performance but that lower levels towards the end are necessary for high performance. Moreover, Peterson and Behfar (2003) showed that prior performance predicts changes in conflicts over time. In line with this research, we examine antecedents that go along with a decrease or increase of conflicts using a longitudinal design.

\section{JOB STRESSORS AND TASK CONFLICTS}

Job stressors are stimuli in the stress process (Jex, 1998; Lazarus \& Folkman, 1984). Especially stressors that are associated with hindrance at work, i.e., stressors that impede goal attainment, are negatively related to job performance, job satisfaction, motivation, and commitment as well as positively related to strain, turnover, and withdrawal (LePine et al., 2005; Podsakoff, LePine, \& LePine, 2007). Meta-analytic results indicate that situational constraints belong to the most dysfunctional job stressors with regard to job performance (Gilboa, Shirom, Fried, \& Cooper, 2008). Situational constraints refer to hassles and obstacles in the work situation that hinder task accomplishment (e.g., incomplete and outdated material and information; Peters \& O'Connor, 1980; Spector \& Jex, 1998).

We propose that situational constraints are related to an increase of task conflicts because they represent potential issues to argue about. Situational constraints indicate that work procedures are not optimal. Typically, employees have little control over these constraints (Jex, 1998; Peters \& O'Connor, 1980). However, employees might attribute this suboptimal functioning to failure of themselves, colleagues, and supervisors or to external reasons. According to causal attribution theory (e.g., Zuckerman, 1979), persons tend to follow a self-serving bias and therefore attribute failure of oneself to external reasons but failure of others to their internal reasons. Translated to situational constraints at work, we argue that employees may hold colleagues and supervisors responsible for these constraints instead of admitting their own fault. As a result, employees will emphasize differences in work accomplishment between themselves and their colleagues and will argue about the right way to accomplish the tasks. Consequently, task conflicts may increase. Additionally, competing for scarce resources, which is one indicator for situational constraints (Peters \& O'Connor, 1980), may increase task conflicts. Research on relationships between job stressors and interpersonal conflicts is scarce as conflicts are often seen as stressors themselves (Giebels \& Janssen, 2005). Taken together, we propose:

Hypothesis 1: Situational constraints are related to increased task conflicts with colleagues and supervisors. 


\section{PROACTIVE WORK BEHAVIOUR AND TASK CONFLICTS}

In general, proactive work behaviour can be defined as discretionary behaviour that aims at changing the internal organizational environment (Parker \& Collins, 2010). For a long time, research studied proactive work behaviour as a general construct, for example as personal initiative (Frese, Kring, Soose, \& Zempel, 1996), general proactive behaviour (Crant, 2000), or taking charge (Morrsion \& Phelps, 1999). More and more, research in this field demonstrates the importance of differentiating particular dimensions and types of proactive behaviour (Grant \& Ashford, 2008; Griffin et al., 2007; Parker \& Collins, 2010). In our study, we focus on two types of proactive work behaviour, namely promotion-oriented initiative and prevention-oriented initiative.

Promotion-oriented initiative includes a broad range of proactive work behaviours that is comparable to behaviours examined in earlier research on proactivity. Based on prior definitions of personal initiative, taking charge, and proactive work behaviour (Frese et al., 1996; Morrison \& Phelps, 1999; Parker, Williams, \& Turner, 2006), we define promotion-oriented initiative as discretionary behaviour that aims at taking control in order to improve the internal organizational environment. From a motivational perspective, promotion-oriented initiative includes a promotion focus, i.e., the pursuit of desired goals (Higgins, 1997). For example, an employee who works in a pension insurance company engages in promotion-oriented initiative by trying to introduce work procedures that are more customer-oriented (e.g., sending a notice of receipt directly after a customer put a question to the company instead of answering the question days or weeks later). Compared to the types of proactive work behaviour introduced by Parker and Collins (2010), promotion-oriented initiative is related to the concept of taking charge.

We define prevention-oriented initiative as discretionary behaviour that aims at preventing the reoccurrence of obstacles and stressors at work. From a motivational perspective, prevention-oriented initiative includes a prevention focus, i.e., the avoidance of undesired outcomes (Higgins, 1997). For example, if several employees have some trouble with new software that is already used in the department and one employee initiates a workshop to share experiences with the software, this employee engages in preventionoriented initiative. Hence, this type of proactive behaviour is not fully self-initiated but is rather a reaction to job stressors. Consequently, prevention-oriented initiative might be seen as a form of proactive coping (Aspinwall \& Taylor, 1997) or innovative coping (Bunce \& West, 1994) and is closely related to the concept of problem prevention as described by Parker and Collins (2010). However, although prevention-oriented initiative overlaps with coping, it additionally includes proactive elements of problem solving 
going beyond solving an acute problem. Overall, the motivational and situational background of the two types of proactive work behaviour is quite different and these types will also relate differently to potential outcome variables.

We propose that promotion-oriented initiative will be related to increased task conflicts while prevention-oriented initiative will be related to decreased task conflicts. Typically, researchers have mostly studied proactive behaviour as work behaviour that is beneficial, and have only rarely addressed potential negative consequences. Early articles discussed potential unanticipated consequences (Bateman \& Crant, 1999; Campbell, 2000) but did not empirically validate the propositions. In this study we focus on potential negative outcomes of proactive work behaviour. Especially with regard to promotion-oriented initiative in contrast to prevention-oriented initiative we propose detrimental effects. Promotion-oriented initiative implies to fulfil additional tasks, to execute existing tasks in a proactive manner, to deal with barriers and setbacks, and sometimes also to offend a company's implicit rules. This behaviour may lead to negative judgements by colleagues and supervisors, who, for example perceived the proactive individual as a "difficult person" who always wants to address more issues than others do. Indeed, Grant et al. (2009) showed that employee proactive behaviour is not always appreciated by supervisors. Furthermore, employees engaging in promotion-oriented initiative may create more workload and more stress objectively, because they challenge role boundaries and introduce new and sometimes more exhausting ways to execute tasks as well as new tasks that would not arise when only fulfilling formal job descriptions. These additional tasks and new ways of task accomplishment may also have an impact on tasks and work processes of colleagues and supervisors as can be seen in the introduced example about an employee who tries to introduce more customer-oriented work procedures (e.g., sending a notice of receipt directly after a customer put a question to the company instead of only answering the question days or weeks later). First, most probably only this employee will behave in this manner but later on colleagues within the same department might have to take over this behaviour as customers and supervisor request it. Thus, working procedures and also workload of colleagues are affected. Therefore, colleagues and supervisors who do not want to engage in promotion-oriented initiative may perceive employees who do so to be responsible for the increase of workload and stress. As a result, conflicts about how to successfully accomplish work will increase due to different opinions about role boundaries and relevant tasks.

Concerning prevention-oriented initiative and task conflicts at work, we argue that prevention-oriented initiative should be related to decreased task conflicts. Although also prevention-oriented initiative goes beyond the formal job description, this kind of behaviour is much more focused on 
solving present and future problems and preventing the reoccurrence of specific job stressors. Following the introduced example, due to the fact that many colleagues repeatedly had problems using a particular pension software package an employee stands up and initiates a workshop to share experiences with this software or convinces his or her supervisor to change the particular software that is used in his or her department. Thus, this behaviour also has an impact on colleagues and supervisors but the probability that colleagues and supervisors take direct advantage of this behaviour is high because their problems may also be solved. Consequently, an employee engaging in prevention-oriented initiative is most probably perceived as the one who solves the problems and reduces stress. Therefore, colleagues and supervisors should be grateful for employees engaging in prevention-oriented initiative and will agree that this is a desired way to deal with work tasks. Thus, task conflicts at work should decrease. Taken together, we propose:

Hypothesis 2: Promotion-oriented initiative is related to increased task conflicts with colleagues and supervisors.

Hypothesis 3: Prevention-oriented initiative is related to decreased task conflicts with colleagues and supervisors.

\section{OVERVIEW OF THE STUDIES}

In Study 1, we developed measures for promotion-oriented and preventionoriented initiative and examined construct validity of these two measures through confirmatory factor analyses. Furthermore, we analysed discriminant and convergent validity of the measures. To test discriminant validity, we distinguished promotion-oriented initiative and prevention-oriented initiative from active coping by confirmatory factor analyses. To test convergent validity, we compared relationships of the newly developed measures to those of the personal initiative scale by Frese, Fay, Hilburger, Leng, and Tag (1997), which is an established measure of proactive behaviour. Moreover, we examined relationships of promotion-oriented initiative, prevention-oriented initiative, and personal initiative on the one hand with variables that are typically related to proactive behaviour (job control, time pressure, situational constraints, job involvement, and active coping) on the other hand (e.g., Bindl \& Parker, 2010; Fay \& Frese, 2001).

Study 2 is the main study of this article. In this study, we tested our hypotheses by examining the relationships of situational constraints and the two types of proactive behaviour with task conflicts at work. For Study 2, we gathered data at different points in time, in order to be able to examine 
change in task conflicts over time. More specifically, we used diary measures to obtain more reliable estimates of the predictor variables (Bolger, Davis, \& Rafaeli, 2003) and predicted change in task conflicts over 2 weeks.

\section{STUDY 1: CONSTRUCT VALIDATION}

\section{Method}

\section{Participants and procedure}

We collected data by paper-and-pencil questionnaires in a sample of student assistants who worked at German universities. We contacted administrative offices of university departments (excluding psychology departments) and asked for an e-mail to be forwarded with information about the study to student assistants working in the departments. We have no information about how many student assistants have been contacted. In sum, 685 master student assistants expressed their willingness to participate in the study. We received complete surveys from 363 student assistants (53.0\%). These student assistants worked on administrative tasks (e.g., IT administration, literature search, data entry), scientific tasks (e.g., carrying out experiments, recruitment of study participants, proof-reading), and teaching (e.g., holding tutorials, consulting students). Mean age was 24.5 years $(S D=2.7$ years); about $49 \%$ were male and $51 \%$ were female, and on average they had worked for 16.3 months as a student assistant ( $S D=12.8$ months).

\section{Measures}

All items were rated on a 5-point Likert scale from 1 ("fully disagree") to 5 ("fully agree") (with the exception of job involvement, which was rated on a 7-point Likert scale).

Proactive behaviour. We used five items to measure promotion-oriented initiative. Scale development was based on the measure of Frese et al. (1997): We adopted three items that are in accordance with the concept of promotion-oriented initiative; we reworded two other items from this measure to create items which focus more strongly on the promotionoriented aspect of proactive behaviour; and we removed two items that are associated with prevention-oriented behaviour (see Table 1). Cronbach's alpha was .79. Prevention-oriented initiative was assessed by five newly generated items that capture proactive dealing with stressors and prevention of their reoccurrence (see Table 1). Cronbach's alpha was .79. We assessed personal initiative by the seven-item scale of Frese et al. (1997). A sample item is "I actively attack problems". Cronbach's alpha was .75. 
TABLE 1

Standardized factor loadings from confirmatory factor analysis for proactive behaviour and active coping (Study 1)

\begin{tabular}{|c|c|c|c|}
\hline \multirow[b]{2}{*}{ Items } & \multicolumn{3}{|c|}{ Factors } \\
\hline & 1 & 2 & 3 \\
\hline \multicolumn{4}{|l|}{ Prevention-oriented initiative } \\
\hline I actively work on disposing obstacles at work once and for all. & .76 & & \\
\hline I try to eliminate obstacles and troubles at work early. & .71 & & \\
\hline $\begin{array}{l}\text { If problems occur at work, I try to solve them in a way that } \\
\text { they cannot happen again. }\end{array}$ & .66 & & \\
\hline I do not wait until others solve the problems, but I become active myself. & .61 & & \\
\hline I often try to prevent the reoccurrence of work stressors. & .55 & & \\
\hline \multicolumn{4}{|l|}{ Promotion-oriented initiative } \\
\hline I am known for taking matters into my own hands at work. & & .74 & \\
\hline I am particularly good at realizing ideas. (Frese et al., 1997) & & .68 & \\
\hline I am a "doer". & & .68 & \\
\hline I use opportunities quickly in order to attain my goals. (Frese et al., 1997) & & .66 & \\
\hline $\begin{array}{l}\text { Whenever there is a chance to get actively involved, I take it. } \\
\text { (Frese et al., 1997) }\end{array}$ & & .56 & \\
\hline \multicolumn{4}{|l|}{ Active coping } \\
\hline I take direct action to get around the problem. & & & .88 \\
\hline I do what has to be done, one step at a time. & & & .58 \\
\hline I concentrate my efforts on doing something about it. & & & .56 \\
\hline I take additional action to try to get rid of the problem. & & & .55 \\
\hline
\end{tabular}

Subsample with $N=311$.

Job control. We measured job control by a five-item scale developed by Semmer (1984) and Zapf (1993) which is widely used in and comprehensively validated for German-speaking countries (Semmer, Zapf, \& Dunckel, 1999; Semmer, Zapf \& Greif, 1996). A sample item is "How much can you influence the way in which you accomplish your tasks?" Cronbach's alpha was .77.

Job stressors. We measured job stressors by scales developed by Semmer (1984) and Zapf (1993) also frequently used in German-speaking countries and comprehensively validated (Semmer et al., 1996, 1999). Time pressure was measured by five items (sample item: "I am required to work fast at my work"). Cronbach's alpha was .85. Situational constraints were assessed by five items (sample item: "I have to work with materials and information that are incomplete and outdated"). Cronbach's alpha was .71.

Job involvement. We measured job involvement by the 10-item scale of Kanungo (1982). A sample item is "Most of my interests are centred on my job". Cronbach's alpha was .87 . 
Active coping. We assessed active coping in a subsample with the corresponding four-item subscale of the COPE inventory (Carver, Scheier, $\&$ Weintraub, 1989). A sample item is "I take direct action to get around the problem". Cronbach's alpha was .73.

\section{Results}

We ran a set of confirmatory factor analyses (CFAs) to test if promotionoriented initiative and prevention-oriented initiative were distinct constructs. A two-factor model with promotion-oriented initiative loading on a first factor and prevention-oriented initiative loading on a second factor showed good fit indices, $\chi^{2}=94.89, d f=34, p<.001, \mathrm{GFI}=.95, \mathrm{NFI}=.92$, $\mathrm{CFI}=.95$, RMSEA $=.07$, and fitted the data significantly better than a onefactor model with promotion-oriented initiative and prevention-oriented initiative loading on one factor, $\Delta \chi^{2}(1)=79.34, p<.001$. The correlation between the observed variables promotion-oriented initiative and prevention-oriented initiative was $r=.61$.

To test discriminant validity, we ran a set of confirmatory factor analyses to test if promotion-oriented initiative and especially prevention-oriented initiative can be distinguished from active coping. Data on active coping were available for a subsample of $N=311$. Table 1 shows factor loadings and Table 2 indicates that a three-factor model, with prevention-oriented initiative loading on the first factor, promotion-oriented initiative loading on the second factor and active coping loading on the third factor, fitted the data well and showed a significantly better fit than the second best model with promotion-oriented initiative and prevention-oriented initiative loading on a first factor and active coping loading on a second factor, $\Delta \chi^{2}(2)=70.49$, $p<.001$. Thus, CFA showed that promotion-oriented initiative and prevention-oriented initiative are distinguishable constructs. Importantly, prevention-oriented initiative is distinct from the construct of active coping.

To test convergent validity of promotion-oriented initiative and prevention-oriented initiative, i.e., to test if both new constructs are still types of proactive behaviour, we compared relationships of the newly developed scales with the personal initiative scale by Frese et al. (1997), which is an established measure of proactive behaviour. More specifically, we compared zero-order correlations of promotion-oriented initiative, prevention-oriented initiative, and personal initiative with variables that had been identified as antecedents of proactive behaviour in earlier research (i.e., job control, time pressure, situational constraints, and job involvement; Fay \& Frese, 2001). Table 3 shows means, standard deviations, and zero-order correlations. Correlation coefficients of promotion-oriented initiative and prevention-oriented initiative with typical antecedents do not differ significantly from correlation coefficients of personal initiative with these 
TABLE 2

Confirmatory factor analyses for proactive behaviour and active coping (Study 1)

\begin{tabular}{lccccccc}
\hline & $\chi^{2}$ & $d f$ & $p$ & $G F I$ & NFI & CFI & RMSEA \\
\hline One-factor model & 395.14 & 77 & .001 & .83 & .72 & .76 & .12 \\
Two-factor model 1 $^{\mathrm{a}}$ & 330.75 & 76 & .001 & .85 & .76 & .80 & .10 \\
Two-factor model 2 $^{\mathrm{b}}$ & 311.50 & 76 & .001 & .86 & .78 & .82 & .10 \\
Two-factor model 3 $^{\mathrm{c}}$ & 196.09 & 76 & .001 & .91 & .86 & .91 & .07 \\
Three-factor model $^{\mathrm{d}}$ & 125.60 & 74 & .001 & .95 & .91 & .96 & .05 \\
\hline
\end{tabular}

Subsample with $N=311$. ${ }^{\text {a }}$ Promotion-oriented initiative items and active coping items loading on first factor and prevention-oriented initiative items loading on second factor. ${ }^{\mathrm{b}}$ Preventionoriented initiative items and active coping items loading on first factor and promotion-oriented initiative items loading on second factor. ${ }^{\mathrm{c}}$ Prevention-oriented initiative items and promotionoriented initiative items loading on first factor and active coping items loading on second factor. ${ }^{\mathrm{d}}$ Prevention-oriented initiative items loading on first factor, promotion-oriented initiative items loading on second factor, and active coping items loading on third factor.

antecedents. Although this might be obvious for promotion-oriented initiative because this measure includes items that are also used in the personal initiative scale, we found similar results for prevention-oriented initiative. Thus, promotion-oriented initiative and prevention-oriented initiative constitute distinguishable types of proactive behaviour while they relate to other variables in a similar way as personal initiative does.

\section{STUDY 2: TEST OF HYPOTHESES}

\section{Method}

\section{Participants and procedure}

We collected data via online surveys in German public health and pension insurance companies. To recruit participants, we contacted CEOs or HR managers of the companies. After having received management consent, employees were provided with written information about the study and a registration form. The study was introduced as examining "stress at work". We have no information about how many employees have been contacted.

After their registration, participants received a link for a general survey via e-mail. This general survey assessed demographic variables and the general level of the examined variables. General survey data constituted "Time 1" data.

Subsequently, participants received daily electronic mails with links to daily surveys on four consecutive working days (Monday to Thursday, constituting "Time 2" data). Each day, the first survey ("morning survey") 
666 SPYCHALA AND SONNENTAG

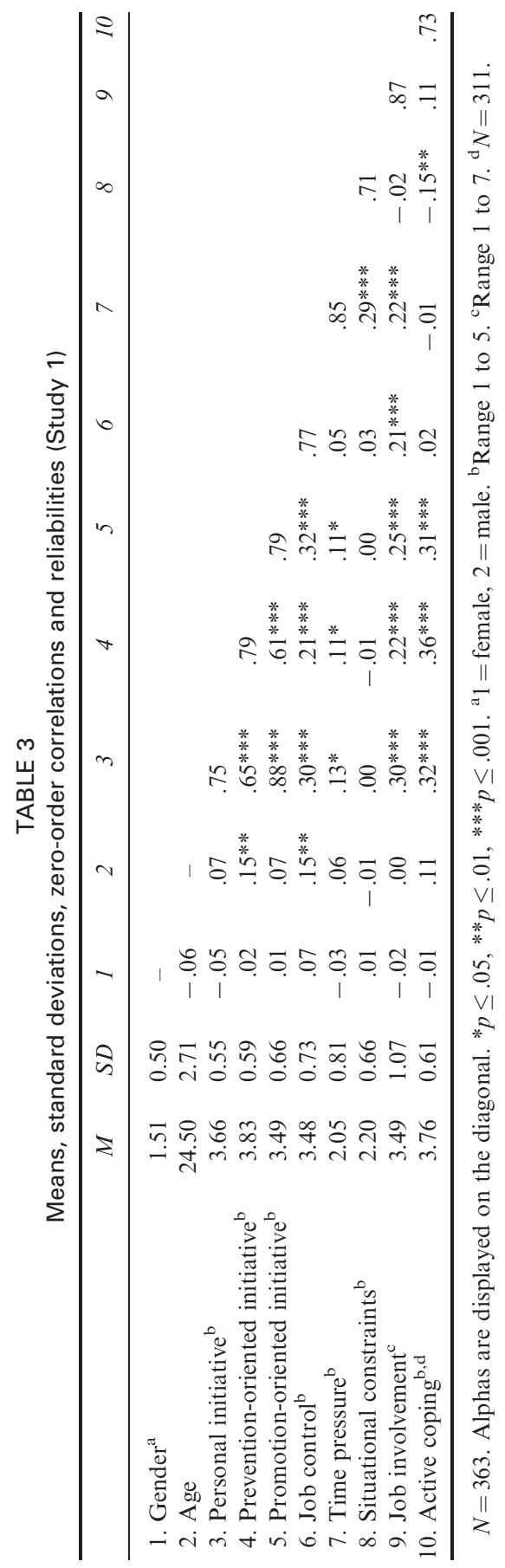


referred to the morning assessments of the examined variables. The link to this survey was sent around lunch break (the exact time was dependent on participants' information about their individual working hours). The second survey ("afternoon survey") referred to the afternoon assessments of the examined variables and the respective link was sent at the end of the working day, immediately before participants went home. Time of completing the surveys was logged automatically. To reduce possible biases that can occur for retrospective evaluations, we averaged daily scores for each participant assessed over the course of the four days for further analyses (Bolger et al., 2003). Thus, "Time 2" data was averaged out of eight measurements during four consecutive working days and therefore reflected employees' average perception of study variables during Week 1.

Finally, participants received a link to the survey "after 2 weeks". The link was sent 2 weeks after the participants completed the last daily survey, i.e., at the end of Week 3. This survey refers to assessments of the examined variables within the last two weeks, i.e., Weeks 2 and 3. Data from this final survey constituted "Time 3". Following Dormann (2007), we chose a relatively short time lag. Dormann argued for conducting more short-term longitudinal studies because effect sizes of longitudinal effects depend on stabilities of independent and dependent variables: The more unstable the variables are, the shorter the time lags have to be.

All in all, 310 employees registered for the study, 299 completed at least one survey $(96.5 \%)$. We received valid data for the general survey, at least for two of the daily surveys and for the after-2-weeks survey from 197 employees from nine public health and pension insurance companies. Dailysurvey data were considered to be valid if we received complete data for the morning and afternoon survey of the respective day with at least 2 hours between both surveys. From the 197 employees, 54\% were female and $46 \%$ were male; $49 \%$ held a university degree, the remaining completed another professional education. Mean age was 39.3 years $(S D=9.9$ years) and mean tenure in the respective company was 14.9 years $(S D=9.0$ years).

\section{Measures}

We assessed demographic control variables (gender, tenure, trait negative affect) with the general survey (Time 1). We measured the other variables with the daily surveys (Time 2) and the survey after 2 weeks (Time 3). All items were rated on a 5-point Likert-scale from 1 ("fully disagree") to 5 ("fully agree"). Items were the same for all questionnaires except for the time frames specified in the instructions to each set of items: Items referred to "in general" in the general survey, "this morning" in the morning survey, "this afternoon" in the afternoon survey, and "during the last 2 weeks" in the final questionnaire at the end of Week 3. 
Situational constraints. As in Study 1, we measured situational constraints by a scale developed by Semmer (1984) and Zapf (1993), which is comprised of five items. Cronbach's alphas ranged from .75 to .84 in the various surveys (general survey, daily surveys, and after-2-weeks survey).

Proactive behaviour. To measure promotion-oriented initiative we used the five items from Study 1. A sample item for the morning survey is "This morning, I used opportunities quickly in order to attain my goals". Cronbach's alphas ranged from .80 to .88 in the various surveys. Preventionoriented initiative was assessed by five items developed for Study 1. A sample item for the morning survey is "This morning, I tried to prevent the reoccurrence of work stressors". Cronbach's alphas ranged from .79 to .92 in the various surveys.

Task conflicts. We measured task conflicts by the task-conflict scale of Giebels and Janssen (2005), which was based on the scale of Jehn (1995). The scale included four items, a sample item is "This morning, me and my colleagues and supervisors had divergent ideas on the execution of tasks". Cronbach's alpha ranged from .86 to .92 in the various surveys.

Control variables. We controlled for gender, tenure, trait negative affect, and Time 2 level of task conflicts to predict change in task conflicts at Time 3. Prior research identified gender and tenure as variables that were related to task conflicts (de Wit \& Greer, 2008; Giebels \& Janssen, 2005; Jehn, 1995). Furthermore, research has shown that men and women differ in their influence on group decisions (Thomas-Hunt \& Phillips, 2004) and in the degree to which they openly engage in task-related discussions at work (Sonnentag \& Volmer, 2009). Therefore, it might be that women, who tend to withhold their views on task-related issues - when they are highly knowledgeable - are less likely to experience task conflicts. In addition, with regard to tenure, new employees might question the working procedures of employees who have already worked in the organization for a long time. In general, they might be careful with criticism and suggestions but they might especially announce these issues if conflicts already exist; thus conflicts may increase. Therefore, we included gender and tenure as control variables in our analyses. Moreover, we controlled for trait negative affect to reduce common method variance (Podsakoff, MacKenzie, Lee, \& Podsakoff, 2003). Podsakoff et al. (2003) discuss this variable as one major source for common method variance and suggest controlling for general negative affectivity. Gender and tenure were assessed by open questions. Trait negative affect was assessed by the respective 10-item scale of the PANAS (sample item: “distressed"; Watson, Clark, \& Tellegen, 1988). Cronbach's alpha was .86. 


\section{Data analysis}

We ran a set of confirmatory factor analyses (CFAs) to test discriminant validity of the two measures of proactive work behaviour. The CFAs were run separately for morning and afternoon questionnaires with person-mean centred variables (Bolger et al., 2003). The two-factor model showed good fit indices (Table 4) and fitted the data significantly better than the one-factor model, $\Delta \chi^{2}(1)=269.47, \quad p<.001$ for morning survey, $\Delta \chi^{2}(1)=315.97$, $p<.001$ for afternoon survey. The correlation between the observed variables promotion-oriented initiative and prevention-oriented initiative was $r=.68$.

To predict change in our outcome variable task conflicts (Time 3) we performed hierarchical regression analyses. We entered control variables (gender, tenure, trait negative affect, Time 2 score of task conflicts) in the first step and the predictor variables (situational constraints, promotionoriented initiative, prevention-oriented initiative, all assessed at Time 2) in the second step. As correlations among the predictor variables were substantial (i.e., greater than $r=.50$ ), we assessed multicollinearity in our data. We examined the tolerance index and the variance inflation factor (VIF) of each predictor in the regression models. Generally, values lower than 0.10 for tolerance index and values greater than 10 for VIF indicate problems with multicollinearity (e.g., Belsley, Kuh, \& Welsch, 1980; Chatterjee \& Hadi, 2006; Marquardt, 1970). VIF values were less than 2.1 , and tolerance values were equal to or greater than .48. Thus, multicollinearity was not a serious problem.

Moreover, following the suggestion of Zapf, Dormann, and Frese (1996), we also examined reverse relationships, i.e., predicting change in situational constraints, promotion-oriented initiative, and prevention-oriented initiative from task conflicts at work. According to Zapf et al., this procedure allows to overcome problems of reverse causation, i.e., a potential alternative

TABLE 4

Confirmatory factor analyses for prevention-oriented initiative and promotion-oriented initiative (Study 2)

\begin{tabular}{lccccccc}
\hline & $\chi^{2}$ & $d f$ & $p$ & $G F I$ & NFI & CFI & RMSEA \\
\hline Morning & & & & & & & \\
$\quad$ One-factor model & 441.38 & 35 & .001 & .85 & .80 & .81 & .14 \\
$\quad$ Two-factor model & 171.91 & 34 & .001 & .94 & .92 & .94 & .08 \\
Afternoon $^{\mathrm{a}}$ & & & & & & & \\
$\quad$ One-factor model $_{\text {Two-factor model }}^{\mathrm{a}}$ & 467.96 & 35 & .001 & .83 & .78 & .79 & .14 \\
\hline
\end{tabular}

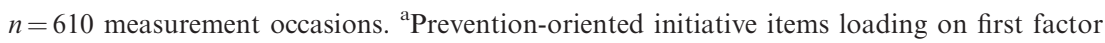
and promotion-oriented initiative items loading on second factor. 
hypothesis stating that the "dependent" variable predicts change in the "independent" variables can be ruled out.

\section{Results}

Table 5 displays means, standard deviations, and zero-order correlations.

We had hypothesized that situational constraints (Hypothesis 1) and promotion-oriented initiative (Hypothesis 2) predict an increase in task conflicts, whereas prevention-oriented initiative predict a decrease (Hypothesis 3). Table 6 shows results for predicting change in task conflicts within 2 weeks. Consistent with Hypotheses 1 and 2, situational constraints and promotionoriented initiative predicted an increase in task conflicts. Supporting Hypothesis 3, prevention-oriented initiative predicted a decrease in task conflicts.

Furthermore, using the same procedure and following Zapf et al. (1996), we tested reverse relationships of the hypothesized relationships, i.e., predicting change in situational constraints, promotion-oriented, and preventionoriented initiative from task conflicts. We found no significant reverse effects, i.e., a potential alternative hypothesis stating that the "dependent" variable predicts change in the "independent" variables can be ruled out.

\section{GENERAL DISCUSSION}

The main goal of this article was to examine antecedents of task conflicts at work with a longitudinal design. We examined relationships of situational constraints and two types of employees' proactive work behaviour with change in task conflicts over time. Moreover, we also wanted to contribute to a deeper understanding of proactive work behaviour itself. Thus, we introduced promotion-oriented initiative and prevention-oriented initiative as two types of proactive behaviour that are related in an opposite manner to task conflicts. As argued, situational constraints and promotion-oriented initiative were related to increased task conflicts and prevention-oriented initiative was related to decreased task conflicts.

Our study provided support for the idea that situational constraints, i.e., obstacles in the work situation that hinder task accomplishment, predict an increase in task conflicts over 2 weeks. Thus, the more situational constraints employees were confronted with the more task conflicts they experienced. Moreover, our results indicate that employees perceived relatively low levels of situational constraints (cf. Table 5). However, even these low levels of situational constraints predicted an increase in task conflicts. This finding emphasizes the importance and severity of situational constraints at work as even few situational constraints seem to be detrimental. One might argue that task conflicts need not be negative per se as they may stimulate open discussions about how to achieve goals (Amason, 1996; Jehn, 1994). 
PROACTIVE BEHAVIOUR AND TASK CONFLICTS 671

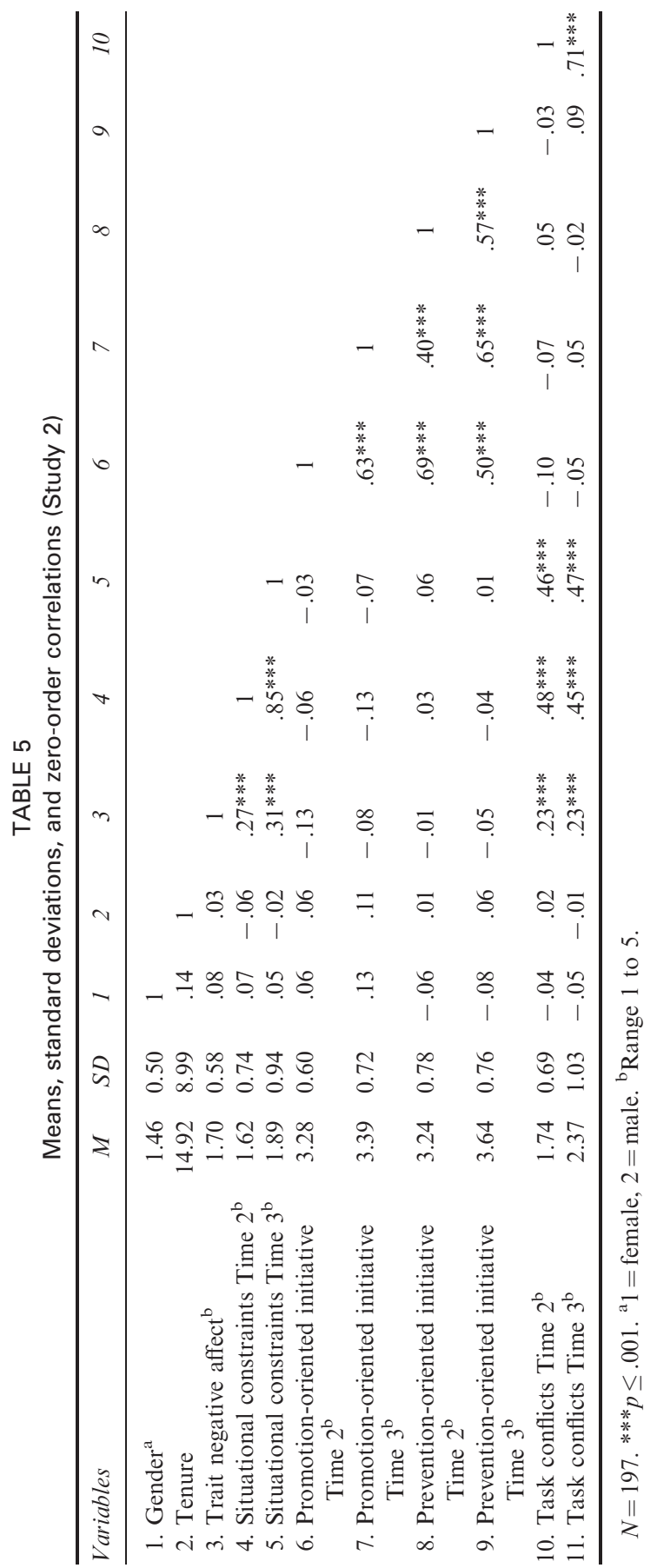


However, more recent research clearly suggests that task conflicts have negative consequences (e.g., de Dreu, 2008; de Dreu \& Weingart, 2003; Friedman et al., 2000; Gamero et al., 2008; Medina et al., 2005). Thus, our result is in accordance with research on hindrance stressors that revealed dysfunctional relationships of hindrance stressors (e.g. situational constraints) with job performance and various job attitudes (Le Pine et al., 2005; Podsakoff et al., 2007). Concerning the conflict literature, our findings imply that not only team composition is relevant for workplace conflict, but attention should also be given to job stressors as antecedents of conflicts.

Concerning proactive behaviour, we found support for treating proactive work behaviour in a more specific way: Promotion-oriented initiative and prevention-oriented initiative were confirmed to be two correlated, albeit clearly distinct types of proactive behaviour. Furthermore, both types have a similar nomological net as personal initiative a proactive behaviour concept suggested by Frese et al. (1997). Moreover, we showed that promotionoriented and prevention-oriented initiativess are distinct from active coping. Thus, although particularly the prevention-oriented initiative concept potentially overlaps with active coping, prevention-oriented initiative goes beyond coping and addresses problems in a proactive manner. Therefore, our study contributes to a broader understanding of proactive work behaviour which is in line with recent studies that suggested distinguishing between several types of proactive work behaviour (Griffin et al., 2007; Parker \& Collins, 2010)

TABLE 6

Hierarchical regression analysis predicting task conflicts over the course of 2 weeks

\begin{tabular}{llr}
\hline & \multicolumn{2}{c}{ Task conflicts at work Time 3 } \\
\cline { 2 - 3 } & \multicolumn{1}{c}{ Step 1 } & Step 2 \\
\hline Step 1 & & \\
$\quad$ Gender ${ }^{\mathrm{a}}$ & -.03 & -.06 \\
Tenure & -.02 & -.01 \\
Trait negative affect Time 1 & .08 & .07 \\
$\quad$ Task conflicts Time 2 & $.69^{* * *}$ & $.64^{* * *}$ \\
Step 2 & & $.14^{*}$ \\
Situational constraints Time 2 & & $.14^{*}$ \\
Promotion-oriented initiative Time 2 & & $-.15^{*}$ \\
Prevention-oriented initiative Time 2 & $.50^{* * *}$ & $.03^{*}$ \\
$\Delta R^{2}$ & & $.53^{* * *}$ \\
Total $R^{2}$ & & \\
\hline
\end{tabular}

$N=197$. Standardized coefficients (beta) are reported. ${ }^{*} p \leq .05,{ }^{* * *} p \leq .001 .{ }^{\mathrm{a}} 1=$ female, $2=$ male. 
We found that promotion-oriented initiative predicted an increase in task conflicts while prevention-oriented initiative predicted a decrease in task conflicts over time. These results challenge the traditional view of proactive work behaviour as behaviour that is globally functional and desirable (Fay \& Frese, 2001). By revealing opposite relationships of different types of proactive work behaviour with a work-related outcome variable we expand our knowledge about proactive behaviour. Although positive consequences of general proactive behaviour concepts (e.g., personal initiative) on performance outcomes are well established in the literature (Fay \& Frese, 2001; Parker et al., 2006; Raabe et al., 2007), we found dysfunctional relationships of promotion-oriented initiative with task conflicts at work. However, prevention-oriented initiative was related to a decrease of task conflicts at work. Thus, consequences of proactive work behaviour seem to be much more complex than earlier research in this field has acknowledged. Moreover, consequences of proactive behaviour might also be dependent on whether an employee's supervisor or colleagues are involved. With regard to research on conflicts at work, this finding implies that employee behaviour is related to changes in task conflicts.

Interestingly, both proactive behaviours predicted a change in task conflicts over time but zero-order correlations were not significant. This indicates that the absolute level of task conflicts does not depend on employees' proactive behaviour but that employees' proactive behaviour might be able to reduce or increase already existing conflicts. In contrast, situational constraints are related to the absolute amount of task conflicts as well as to an increase. Moreover, one might expect a positive correlation between prevention-oriented initiative and situational constraints (Fay \& Sonnentag, 2002), which was not supported by our data. One might speculate that on the one hand, situational constraints trigger prevention-oriented initiative. But on the other hand, this kind of proactive behaviour might reduce situational constraints. If both processes are comparably high, no significant zeroorder correlation will occur. Moreover, one might speculate that situational constraints are not always sufficient for being proactive. For example, employees facing situational constraints may only show prevention-oriented initiative when they have a high level of role-breadth self-efficacy (Parker, 1998) or when they experience a high level of work engagement (Sonnentag, 2003).

Particularly with respect to proactive work behaviour, one might argue that task conflicts impede motivation and therefore reduce proactive behaviour of employees. However, reverse regression effects were not significant, i.e., task conflicts did not predict changes in proactive work behaviour nor in situational constraints. 


\section{Strength and limitations}

Our study is characterized by several strengths but also limitations. One strength of our study is that we used a longitudinal design to test our hypotheses. We gathered data at different points of time and could therefore predict change in task conflicts. Moreover, Time 2 data was averaged out of eight measurements on four consecutive working days. Therefore, we obtained reliable estimates of the predictors throughout participants' working days (Bolger et al., 2003). In sum, the longitudinal design rules out several alternative explanations of our findings, for instance, measurement context effects (Podsakoff et al., 2003).

A central limitation of our study is the use of self-report measures. However, at least concerning individual appraisals of variables such as proactive work behaviour, self-ratings seem to be the best way because proactive behaviour is a discretionary behaviour and colleagues and supervisors might not always be able to fully observe and evaluate this behaviour. Moreover, by partialling out general negative affectivity and by using the initial level of our outcome variable as additional control variable, we followed recommendations of Podsakoff et al. (2003) to reduce the impact of common method variance. Furthermore, internal validity might be reduced because of the retrospective measurement of our outcome variable. Although we used averaged daily scores for our predictor variables (Bolger et al., 2003), we measured task conflicts as outcome variable with a single measurement occasion 2 weeks later. However, usually questionnaire studies rely on single measurement occasions. Therefore, our results are comparable to prior findings concerning task conflicts (e.g., Giebels \& Janssen, 2005; Moye \& Langfred, 2004; Peterson \& Behfar, 2003). Moreover, the zero-order correlation between task conflicts assessed at Time 2 and Time 3 was substantial $(r=.71, p<.001)$ suggesting that a participant's relative score in task conflicts (compared to the whole sample) assessed at Time 2 corresponds closely to this person's relative score at Time 3 .

\section{Future research and practical implications}

Previous conflict research primarily focused on conflict outcomes as well as on conflict management (Spector \& Bruk-Lee, 2008). Research that took antecedents of conflicts into account mainly focused on characteristics of team composition, especially team diversity, which play an important role for conflicts. Along with two other studies (Moye \& Langfred, 2004; Peterson \& Behfar, 2003), our study revealed other factors as antecedents of task conflicts: the work environment (our study: situational constraints), employees' individual behaviour (our study: two types of proactive work behaviour; Moye \& Langfred, 2004: information sharing), and employees' 
prior performance (Peterson \& Behfar, 2003). Therefore, future research should systematically examine various factors as antecedents of conflicts.

In this study, we focused on task conflicts at work. However, prior research differentiated relationship conflicts, and recently also process conflicts, from task conflicts (e.g., Jehn \& Mannix, 2001); Bruk-Lee and Spector (2006) emphasized that team conflicts, which occur on the same hierarchical level, might be different from conflicts between supervisors and subordinates. Thus, future research is necessary to examine if results may be generalized to other types of conflicts and types of opponents in a conflict.

Moreover, investigating potential moderators in the relationship between task conflicts and their antecedents might be fruitful. For instance, personality of employees, employees' and an organization's values, or conflict management styles might buffer negative relationships between situational constraints and promotion-oriented initiative on the one hand and task conflicts on the other hand.

As this study showed differences within proactive work behaviour, future research should continue to investigate different types of proactive work behaviour. In our study, we focused on a promotion-oriented type of proactive work behaviour and on a prevention-oriented type, which takes increase of job stress of today's jobs into account as it aims at avoiding the reoccurrence of job stressors. Also other classifications may be plausible, for example, Parker and Collins (2010) identified four different types of proactive behaviour building a higher order factor proactive work behaviour, Den Hartog and Belschak (2007) suggested different foci of proactive behaviour (pro-self vs. pro-organization), and Griffin et al. (2007) distinguished proactivity that is focused on the individual task from proactivity that is focused on team members or organization members. Closely related, by examining different types of proactive work behaviour, a broader range of potential outcome variables ought to be considered, including work-related attitudes, turnover intention, or employees' mental and physical health. Moreover, longitudinal studies with other time frames are encouraged (e.g., Binnewies, Sonnentag, \& Mojza, 2009).

From a practical perspective, an unconditional call for engaging in proactive work behaviour has to be challenged. Although proactive work behaviour might contribute to individual and firm success (Fay \& Frese, 2001; Parker et al., 2006; Raabe et al., 2007), potential negative consequences also have to be taken into account. First findings point to an increase of task conflicts at work after engaging in a more promotion-oriented type of proactive work behaviour. To utilize positive outcomes of proactive work behaviour, incorporation of a compatible organizational culture might be helpful, for instance, managers might support an organizational climate for taking initiative (Baer \& Frese, 2003). Furthermore, results of this study have implications for conflict management. Trying to avoid conflicts at work may be 
more beneficial than trying to deal with them when they have already occurred. As stressors, such as situational constraints, are related to increased task conflicts, managers may improve conflict management by addressing potential job stressors. By reducing job stressors fewer task conflicts at work may appear.

\section{CONCLUSION}

Altogether, this study revealed aspects from various domains, such as the work environment (situational constraints) and employees' individual behaviour (two types of proactive work behaviour), as longitudinal antecedents of task conflicts at work. Situational constraints as well as promotion-oriented initiative predicted an increase of task conflicts, whereas prevention-oriented initiative predicted a decrease of task conflicts. Moreover, this study contributes to a deeper understanding of proactive work behaviour by confirming opposite relationships of promotion-oriented and prevention-oriented initiative with task conflicts and therefore probably also for the smooth functioning of work groups. Thus, this study empirically shows that proactive work behaviour may not only be beneficial.

\section{REFERENCES}

Amason, A. C. (1996). Distinguishing the effects of functional and dysfunctional conflict on strategic decision making: Resolving a paradox for top management teams. Academy of Management Journal, 39, 123-148.

Armenakis, A. A., \& Bedeian, A. G. (1999). Organizational change: A review of theory and research in the 1990's. Journal of Management, 25, 293-315.

Aspinwall, L. G., \& Taylor, S. E. (1997). A stitch in time: Self-regulation and proactive coping. Psychological Bulletin, 121, 417-436.

Baer, M., \& Frese, M. (2003). Innovation is not enough: Climates for initiative and psychological safety, process innovations, and firm performance. Journal of Organizational Behavior, 24, 45.

Balogun, J., \& Johnson, G. (2004). Organizational restructuring and middle manager sensemaking. Academy of Management Journal, 47, 523-549.

Bateman, T. S., \& Crant, J. M. (1993). The proactive component of organizational behavior: A measure and correlates. Journal of Organizational Behavior, 14, 103-118.

Bateman, T. S., \& Crant, J. M. (1999). Proactive behavior: Meaning, impact, recommendations. Business Horizons, 42, 63-70.

Belsley, D. A., Kuh, E. \& Welsch, R. E. (1980). Regression diagnostics: Identifying influential data and sources of collinearity. New York: Wiley.

Bindl, U. K., \& Parker, S. K. (2010). Proactive work behavior: Forward-thinking and changeoriented action in organizations. In S. Zedeck (Ed.), APA handbook of industrial and organizational psychology:Vol. 2. Selecting and developing members for the organization (pp. 567-598). Washington, DC: American Psychological Association.

Binnewies, C., Sonnentag, S., \& Mojza, E. J. (2010). Recovery during the weekend and fluctuations in weekly job performance: A week-level study examining intra-individual relationships. Journal of Occupational and Organizational Psychology, 82(2), 419-441. 
Bolger, N., Davis, A., \& Rafaeli, E. (2003). Diary methods: Capturing life as it is lived. Annual Review of Psychology, 54, 579-616.

Bruk-Lee, V., \& Spector, P. (2006). The social stressors-counterproductive work behaviors link: Are conflicts with supervisors and coworkers the same? Journal of Occupational Health Psychology, 11, 145-156.

Bunce, D., \& West, M. (1994). Changing work environments: Innovative coping responses to occupational stress. Work and Stress, 8, 319-331.

Campbell, D. J. (2000). The proactive employee: Managing workplace initiative. Academy of Management Executive, 14, 52-66.

Carver, C., Scheier, M., \& Weintraub, J. (1989). Assessing coping strategies: A theoretically based approach. Journal of Personality and Social Psychology, 56, 267-283.

Chatterjee, S., \& Hadi, A. S. (2006). Regression analysis by example (4th ed.). New York: Wiley.

Crant, J. (2000). Proactive behavior in organizations. Journal of Management, 26, 435-462.

De Dreu, C. (2008). The virtue and vice of workplace conflict: Food for (pessimistic) thought. Journal of Organizational Behavior, 29, 5-18.

De Dreu, C., \& Weingart, L. (2003). Task versus relationship conflict, team performance, and team member satisfaction: A meta-analysis. Journal of Applied Psychology, 88, 741749 .

Den Hartog, D. N., \& Belschak, F. D. (2007). Personal initiative, commitment and affect at work. Journal of Occupational and Organizational Psychology, 80, 601-622.

De Wit, F., \& Greer, L. (2008). The black-box deciphered: A meta-analysis of team diversity, conflict, and team performance. Academy of Management Proceedings.

Dormann, C. (2007, May). Sustainable WO-psychology research: An illusion? Why short-term effects matter more! Paper presented at the XIIIth European Congress of Work and Organizational Psychology, Stockholm.

Fay, D., \& Frese, M. (2001). The concept of personal initiative: An overview of validity studies. Human Performance, 14, 97-124.

Fay, D., \& Sonnentag, S. (2002). Rethinking the effects of stressors: A longitudinal study on personal initiative. Journal of Occupational Health Psychology, 7, 221-234.

Frese, M., Fay, D., Hilburger, T., Leng, K., \& Tag, A. (1997). The concept of personal initiative: Operationalization, reliability and validity of two German samples. Journal of Occupational and Organizational Psychology, 70, 139-161.

Frese, M., Kring, W., Soose, A., \& Zempel, J. (1996). Personal initiative at work: Differences between East and West Germany. Academy of Management Journal, 39, 37-63.

Friedman, R. A., Tidd, S. T., Currall, S. C., \& Tsai, J. C. (2000). What goes around comes around: The impact of personal conflict style on work conflict and stress. International Journal of Conflict Management, 11, 32-55.

Gamero, N., González-Romá, V., \& Peiró, J. (2008). The influence of intra-team conflict on work teams' affective climate: A longitudinal study. Journal of Occupational and Organizational Psychology, 81, 47-69.

Giebels, E., \& Janssen, O. (2005). Conflict stress and reduced well-being at work: The buffering effect of third-party help. European Journal of Work and Organizational Psychology, 14, 137155.

Gilboa, S., Shirom, A., Fried, Y., \& Cooper, C. (2008). A meta-analysis of work demand stressors and job performance: Examining main and moderating effects. Personnel Psychology, 61, 227-271.

Grant, A. M., \& Ashford, S. J. (2008). The dynamics of proactivity at work. Research in Organizational Behavior, 28, 3-34.

Grant, A. M., Parker, S. K., \& Collins, C. G. (2009). Getting credit for proactive behavior: Supervisor reactions depend on what you value and how you feel. Personnel Psychology, 62, 31-55. 
Greer, L. L., Jehn, K. A., \& Mannix, E. A. (2008). Conflict transformation: A longitudinal investigation of the relationship between different types of intragroup conflict and the moderating role of conflict resolution. Small Group Research, 39, 278-302.

Griffin, M. A., Neal, A., \& Parker, S. K. (2007). A new model of work role performance: Positive behavior in uncertain and interdependent contexts. Academy of Management Journal, 5, 327-347.

Higgins, E. (1997). Beyond pleasure and pain. The American Psychologist, 52, 1280-1300.

Härenstam, A., Bejerot, E., Leijon, O., Schéele, P., Waldenström, K., \& MOA Research Group. (2004). Multilevel analysis of organizational change and working conditions in public and private sector. European Journal of Work and Organizational Psychology, 13, 305-343.

Jehn, K. (1994). Enhancing effectiveness: An investigation of advantages and disadvantages of value-based intragroup conflict. International Journal of Conflict Management, 5, 223-238.

Jehn, K. (1995). A multimethod examination of the benefits and detriments of intragroup conflict. Administrative Science Quarterly, 40, 256-282.

Jehn, K., \& Mannix, E. (2001). The dynamic nature of conflict: A longitudinal study of intragroup conflict and group performance. Academy of Management Journal, 44, 238-251.

Jex, S. (1998). Stress and job performance: Theory, research, and implications for managerial practice. Thousand Oaks, CA: Sage.

Jimmieson, N., Terry, D., \& Callan, V. (2004). A longitudinal study of employee adaptation to organizational change: The role of change-related information and change-related selfefficacy. Journal of Occupational Health Psychology, 9, 11-27.

Kanungo, R. (1982). Measurement of job and work involvement. Journal of Applied Psychology, 67, 341-349.

Lazarus, R. S., \& Folkman, S. (1984). Stress, appraisal, and coping. New York: Springer.

LePine, J. A., Podsakoff, N. P., \& LePine, M. A. (2005). A meta-analytic test of the challenge stressor-hindrance stressor framework: An explanation for inconsistent relationships among stressors and performance. Academy of Management Journal, 48, 764-775.

Marquardt, D. W. (1970). Generalized inverses, ridge regression and biased linear estimation. Technometrics, 12, 591-612.

Medina, F. J., Munduate, L., Dorado, M. A., Martínez, I., \& Guerra, J. M. (2005). Types of intragroup conflict and affective reactions. Journal of Managerial Psychology, 20, 219-230.

Morrison, E. W., \& Phelps, C. C. (1999). Taking charge at work: Extrarole efforts to initiative workplace change. Academy of Management Journal, 42, 403-419.

Moye, N., \& Langfred, C. (2004). Information sharing and group conflict: Going beyond decision making to understand the effects of information sharing on group performance. International Journal of Conflict Management, 15, 381-410.

Parker, S. K. (1998). Enhancing role breadth self-efficacy: The roles of job enrichment and other organizational interventions. Journal of Applied Psychology, 83, 835-852.

Parker, S. K. (2000). From passive to proactive motivation: The importance of flexible role orientations and role breadth self-efficacy. Applied Psychology: An International Review, 49, 447-469.

Parker, S. K., \& Collins, C. G. (2010). Taking stock: Integrating and differentiating multiple forms of proactive behavior. Journal of Management, 36(3), 663-662.

Parker, S. K., Williams, H. M., \& Turner, N. (2006). Modeling the antecedents of proactive behaviour at work. Journal of Applied Psychology, 91, 636-652.

Peters, L. H., \& O'Connor, E. J. (1980). Situational constraints and work outcomes: The influences of a frequently overlooked construct. Academy of Management Review, 5, 391397.

Peterson, R., \& Behfar, K. (2003). The dynamic relationship between performance feedback, trust, and conflict in groups: A longitudinal study. Organizational Behavior and Human Decision Processes, 92, 102-112. 
Podsakoff, N. P., LePine, J. A., \& LePine, M. A. (2007). Differential challenge stressorhindrance stressor relationships with job attitudes, turnover intentions, turnover, and withdrawal behaviour: A meta-analysis. Journal of Applied Psychology, 92, 438-454.

Podsakoff, P., MacKenzie, S., Lee, J., \& Podsakoff, N. (2003). Common method biases in behavioral research: A critical review of the literature and recommended remedies. Journal of Applied Psychology, 88, 879-903.

Raabe, B., Frese, M., \& Beehr, T. A. (2007). Action regulation theory and career selfmanagement. Journal of Vocational Behavior, 70, 297-311.

Schilling, M. A., \& Steensma, H. K. (2001). The use of modular organizational forms: An industry-level analysis. Academy of Management Journal, 44, 1149-1168.

Semmer, N. (1984). Streßbezogene Tätigkeitsanalyse [Stress-oriented task analysis]. Weinheim, Germany: Beltz.

Semmer, N., Zapf, D., \& Dunckel, H. (1999). Instrument zur stressbezogenen Tätigkeitsanalyse (ISTA) [Instrument for stress-oriented task analysis (ISTA)]. In H. Dunckel (Ed.), Handbuch psychologischer Arbeitsanalyseverfahren [Handbook of psychological work analysis methods] (pp. 179-204). Zürich, Switzerland: VdF Hochschulverlag.

Semmer, N., Zapf, D., \& Greif, S. (1996). "Shared job strain": A new approach for assessing the validity of job stress measurements. Journal of Occupational and Organizational Psychology, 69, 293-310.

Simons, T. L., \& Peterson, R. S. (2000). Task conflict and relationship conflict in top management teams: The pivotal role of intragroup trust. Journal of Applied Psychology, 85, $102-111$.

Sonnentag, S. (2003). Recovery, work engagement, and proactive behaviour: A new look at the interface between nonwork and work. Journal of Applied Psychology, 88, 518-528.

Sonnentag, S., \& Volmer, J. (2009). Individual-level predictors of task-related teamwork processes: The role of expertise and self-efficacy in team meetings. Group and Organization Management, 34, 37-66.

Spector, P. E., \& Bruk-Lee, V. (2008). Conflict, health, and well-being. In C. K. W. D. Dreu \& M. J. Gelfand (Eds.), The psychology of conflict and conflict management in organizations (pp. 267-288). New York: Lawrence Erlbaum Associates, Inc.

Spector, P. E., \& Jex, S. (1998). Development of four self-report measures of job stressors and strain: Interpersonal Conflict at Work Scale, Organizational Constraints Scale, Quantitative Workload Inventory, and Physical Symptoms Inventory. Journal of Occupational Health Psychology, 3, 356-367.

Swan, E., \& Fox, S. (2009). Becoming flexible: Self-flexibility and its pedagogies. British Journal of Management, 20, S149-S159.

Thatcher, S. M. B., \& Zhu, X. (2006). Changing identities in a changing workplace: Identification, identity enactment, self-verification, and telecommuting. Academy of Management Review, 31, 1076-1088.

Thomas-Hunt, M. C., \& Phillips, K. W. (2004). When what you know is not enough: Expertise and gender dynamics in task groups. Personality and Social Psychology Bulletin, 30, 15851598.

Watson, D., Clark, L. A., \& Tellegen, A. (1988). Development and validation of brief measures of positive and negative affect: The PANAS scales. Journal of Personality and Social Psychology, 54, 1063-1070.

Zapf, D. (1995). Stress-oriented analysis of computerized office work. In J. M. Peiró, F. Prieto, J. L. Meliá, \& O. Luque (Eds.), Work and organizational psychology: European contributions of the nineties (pp. 61-76). Oxford, UK: Taylor \& Francis.

Zapf, D., Dormann, C., \& Frese, M. (1996). Longitudinal studies in organizational stress research: A review of the literature with reference to methodological issues. Journal of Occupational Health Psychology, 1, 145-169. 


\section{SPYCHALA AND SONNENTAG}

Zuckerman, M. (1979). Attribution of success and failure revisited, or: The motivational bias is alive and well in attribution theory. Journal of Personality, 47, 245-287.

Original manuscript received May 2009 Revised manuscript received May 2010 First published online September 2011 